\title{
Study on Control Strategies of Adjustable Blade Angle Control System
}

\author{
Yu Xiaotao ${ }^{1, ~ a ~}$, Li Zhipeng ${ }^{2, \text { b }}$, Ding Jian ${ }^{3, c}$ \\ ${ }^{1}$ AVIC Shenyang Engine Design and Research institute, Shenyang, 110015, China \\ ${ }^{2}$ AVIC Shenyang Engine Design and Research institute, Shenyang, 110015, China \\ ${ }^{3}$ AVIC Shenyang Engine Design and Research institute, Shenyang, 110015, China \\ aemail: yxt198511@163.com, bemail:lizhipengpdf@sina.com, cemail:583620507@qq.com
}

Keywords: angle control; self-adapting; fuzzy control; MATLAB simulation

\begin{abstract}
In this article, a type of adjustable blade angle control system was designed. The main role of the system was to achieve the function which made the blade angle follow with the change of the signal input. The article indicated the working principle of the adjustable blade angle control system combined with the relative math model. Aiming to the control target, a self-adapting fuzzy PID controller was designed. Mtalab7.0 was applied to carry out simulation and analysis on the cases that the step signals and sine signals were added to the controller, and it was validated that the self-adapting fuzzy PID controller had a good quality of dynamical characteristics, static characteristics and robust characteristics.
\end{abstract}

\section{Introduction}

To improve the aeroengine's performance, widen the working range, the designers developed adjustable blade angle control technology. Nowadays the adjustable blade technology mainly achieved its blade angle following the given signal to carry out follow-up control function through adjustable blade angle control system. This article aimed to the requirements of aeroengine to the blade angle control, developed a set of adjustable blade angle control system. To realize the requirement for the adjustable blade technology as a fast and accuracy respond, this system took hydraulic control into use. Hydraulic control played a very important role in military affairs, aviation and industrial automation.

In practical applications, general requirement was that the controller had fast respond and small overshoot characteristics. Considering that there were some uncertain factors in the hydraulic servo system, the time-changing characteristics of some parameters such as hydraulic nature frequency of the system, hydraulic damping ratio as well as nonlinearity of the servo valves and disturbance of exoteric load, traditional PID controllers could hardly satisfy the control's need, sometimes even not able to be used, while self-adapting fuzzy PID controller was able to simplify the complexity of system design in an extreme degree, which was especially suitable to this kind of nonlinear system control. For this reason this system applied self-adapting fuzzy PID controller as governor [1] [2].

This article applied MATLAB7.0 to carry out simulation and analysis for the case with no disturbs to validate that the self-adapting fuzzy PID controller had better dynamical characteristics, static characteristics and robust characteristics. By practical application, the validity of the designed self-adapting fuzzy PID controller was proved and was able to satisfy the requirements of blade adjusting during the process of the tests.

\section{The working principle of the angle control system}

The control principle of the adjustable blade angle control system was shown in Fig.1. The computer exported the control signal to the A/D conversion module through the RS232 port and transformed it into voltage signal. The voltage signal and signal fed back by the displacement transducer were compared in the servo amplifier, the deviation signal was transformed into current signal after amplified, and transferred to the loop of the electro-hydraulic servo valve, in this way the opening control of the servo valve was achieved. After the servo valve opened, hydraulic oil 
flowed into the actuating cylinder through the valve, made the actuating cylinder move and then achieved angle adjusting. The displacement transducer fixed on the actuating cylinder was used to measure the displacement of the actuating cylinder, and feedback to the servo amplifier.

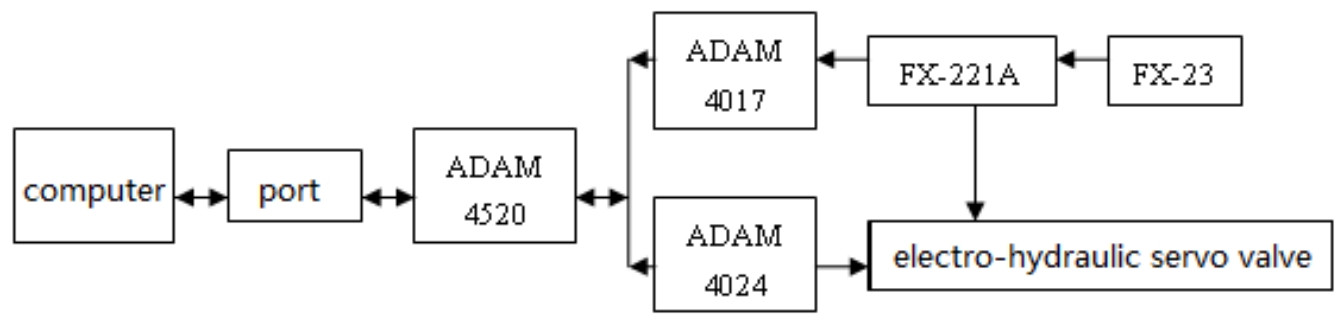

Fig.1. Control principle figure

\section{The mathematical model of angle control system}

Adjustable blade angle control system applied hydraulic pressure to control a pair of hydraulic actuating cylinders, this system included: servo amplifier, electro-hydraulic servo valve, displacement transducer, hydraulic pressure actuating cylinder, etc. The math models for these components were built up as followed:

\section{Servo amplifier}

When using current feedback amplifier, the output current $I_{1}$ and input voltage $U_{1}$ from the power amplifier were approximately proportioned and could be seen as scaled loop, the math model was:

$I_{1}(s)=K_{1} U_{1}(s)$

In the formula $K_{1}$ was servo amplifier increment, the enlargement factor of the servo amplifier $K_{1}=10 \mathrm{~mA} / \mathrm{V}$.

\section{Electro-hydraulic servo valve}

Generally servo valve used current increment $\Delta I$ as input, and no-load flow $Q_{0}$ as output, when the working frequency of the servo valve was nearly the same as hydraulic pressure natural frequency, the servo valve could be seen as a second order surge loop:

$$
\frac{Q_{0}(s)}{\Delta I(s)}=\frac{K_{s v}}{\frac{s^{2}}{\omega_{s v}{ }^{2}}+\frac{2 \xi_{s v}}{\omega_{s v}} s+1}
$$

When the working frequency of the servo valve was larger than the hydraulic pressure natural frequency (3 to 5 times), servo valve could be seen as inertia loop:

$$
\frac{Q_{0}(s)}{\Delta I(s)}=\frac{K_{s v}}{T_{s v} s+1}
$$

When the working frequency of the servo valve was far larger than the hydraulic pressure natural frequency (5 to 10 times), servo valve could be seen as ratio loop:

$$
\frac{Q_{0}(s)}{\Delta I(s)}=K_{s v}
$$

In the formula:

$Q_{0}$ - the no load flow of the servo valve $\left(\mathrm{m}^{3} / \mathrm{s}\right)$;

$\Delta I$ - the input current increment of the servo valve(A);

$K_{s v}$ - the floe increment of the servo valve $\left(\mathrm{m}^{3} / \mathrm{s} \bullet A\right)$;

$\omega_{s v}$ - the natural frequency of the servo valve(rad/s);

$\xi_{s v}$ - the damping ratio of the servo valve;

$T_{s v}$ - the time constant of the servo valve(s).

Generally the respond speed of the electro-hydraulic servo valve was fast. Compared with the 
hydraulic pressure power component, its dynamical characteristics could be out of calculation and seen as ratio loop.

The performance indexes of the servo-valve were as follow:

No-load rated current: $\Delta I=40 \mathrm{~mA}$;

No-load rated flow: $Q_{0}=180 \mathrm{~L} / \mathrm{min}$.

From thoes the flow increment $K_{s v}$ of the servo valve was obtained:

$$
K_{s v}=\frac{Q_{0}}{\Delta I}=0.0756\left(\mathrm{~m}^{3} / \mathrm{s} \cdot A\right)
$$

\section{Displacement transducer}

The displacement transducer could be seen as a ratio loop:

$$
U_{2}(s)=K_{2} Y(s)
$$

In the formula:

$$
U_{2} \text { - voltage signal(V); }
$$

$K_{2}$ - voltage displacement coefficient of the transducer;

$Y$ - displacement(m).

The measurement range of the displacement transducer in practical system was:0-40mm, the relative transducer output voltage was: $0-10 \mathrm{~V}$, so the voltage displacement coefficient $K_{2}=0.25 \mathrm{~V} / \mathrm{mm}$.

\section{Hydraulic pressure actuating cylinder}

With three basic equations of valve-control dissymmetry hydraulic cylinder: flow equation of the slide valve, continuity equation of the hydraulic cylinder flow, equilibrium equation of hydraulic cylinder and load, the transfer function of hydraulic cylinder piston displacement $Y_{p}$ to valve heart displacement $X_{v}$ was deduced as:

$$
G(s)=\frac{Y(s)}{X_{v}(s)}=\frac{K_{s v} / A_{p}}{s\left(\frac{s^{2}}{\omega_{n}^{2}}+\frac{2 \xi_{n}}{\omega_{n}} s+1\right)}
$$

$\omega_{n}$-hydraulic natural frequency;

$\xi_{n}$-hydraulic damping ratio;

$A_{p}$-hydraulic cylinder average poison area;

$K_{s v}$ - flow increment of the servo valve.

\section{Math model simplification}

Not considering the external load influence for the electro-hydraulic position servo valve, the system pane was shown as Fig.2:

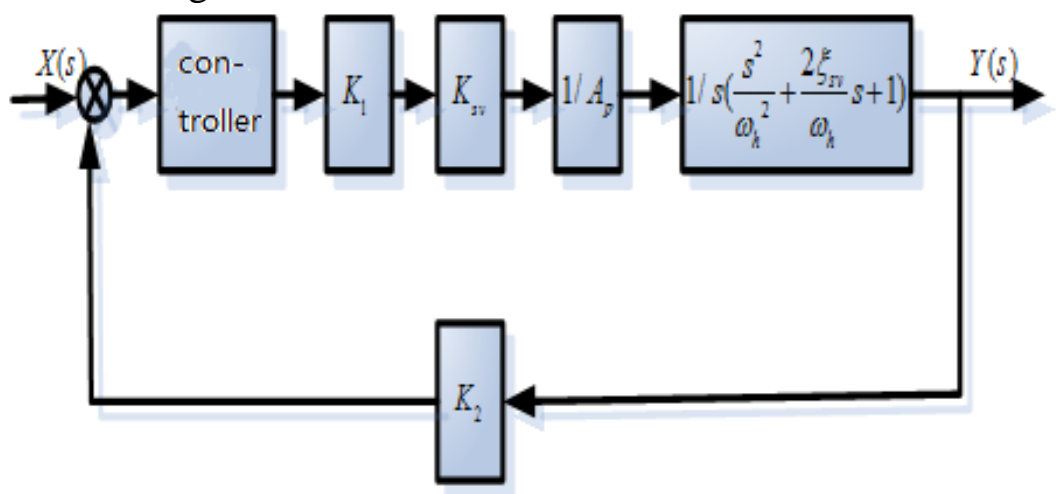

Fig.2. Control system pane 


\section{Controller design and simulation}

The structure of self-adapting fuzzy PID controller was shown in Fig.3. The core of the self-adapting fuzzy PID controller was to apply PID controller to control system. The inputs of the fuzzy deduction was deviation and deviation varying rate ec, after fuzzy deduction three parameters of PID controller, namely $K_{p}, K_{i}, K_{d}$ were auto modified in the parameter modification stage to satisfy the system requirement. It could be seen that since the fuzzy deduction and parameter modification stages were added, even with different control system a good control result was able to be achieved by online setting modifying parameters, meanwhile by using this control method not only the controlled object had a good dynamical performance but also had a good static performance [3] [4] [5].

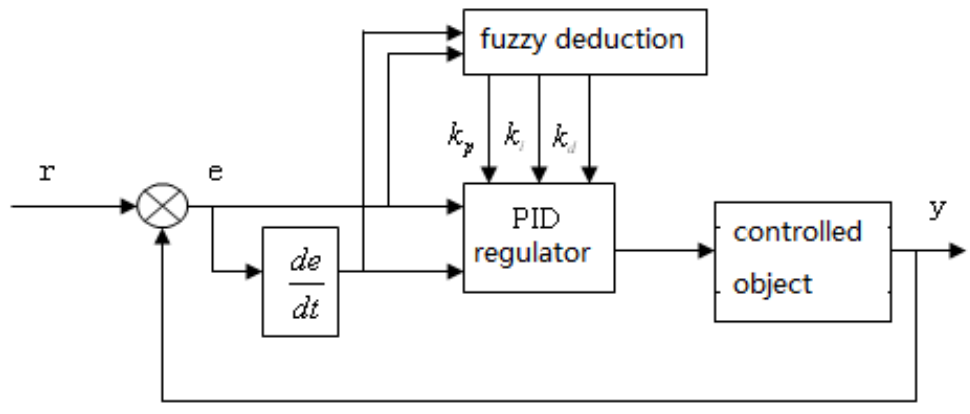

Fig.3. Self-adapting fuzzy PID controller

When using deviation and deviation varying rate to indicate a PID control, the representation was:

$u(k)=K_{p} e(k)+K_{i} \sum e(k)+K_{d} e c(k)$

Where $u(k)$ was controller output, $e(k)$ was deviation, $e c(k)$ was deviation varying rate, $K_{p}$ was scale coefficient, $K_{i}$ was integral action coefficient, $K_{d}$ was derivative action coefficient.

The calculation formulas that this system achieved self-adjusting PID parameters were as follow:

$$
\begin{aligned}
& K_{p}=K_{p}^{\prime}+\Delta K_{p} \\
& K_{i}=K_{i}^{\prime}+\Delta K_{i} \\
& K_{d}=K_{d}^{\prime}+\Delta K_{d}
\end{aligned}
$$

Where $K_{p}^{\prime}, K_{i}^{\prime}, K_{d}^{\prime}$ were PID initial values, $\Delta K_{p}, \Delta K_{i}, \Delta K_{d}$ were the fuzzy controller's outputs, $K_{p}, K_{i}, K_{d}$ were the final output control parameters.

From the above we knew that self-adapting PID was to find the fuzzy relationships among three parameters $K_{p}, K_{i}, K_{d}$ and e as well as ec, kept checking e and ec during the operation, based on the fuzzy principle to carry out online modification for the three parameters to satisfy different requirements for control parameters with different e and ec so that the controlled object had good dynamical and static characteristics. In the following sections design method for this system controller would be described particularly.

\section{Determine input and output varieties}

The deviation e and deviation varying rate ec of this system were taken as inputs, $K_{p}, K_{i}, K_{d}$ were three outputs of the fuzzy controller. According to accurate degree and control requirement, the fuzzy set of input varieties e, ec and output variety $K_{p}, K_{i}, K_{d}$ was \{NB,NM,NS,ZO,PS, $\mathrm{PM}, \mathrm{PB}\}$, the domain was $\{-6,-5,-4,-3,-2,-1,0,1,2,3,4,5,6\}$, the membership function of each variety was chosen to be deltoid membership function.

Fuzzy controlling regular

The principal to determine the fuzzy controlling regular was to achieve the best control effect, in 
the practice the buildup of the fuzzy controller regular was concluded based on the experience from operating staff and experts.

The value of scale coefficient $K_{p}$ was related to the responding speed of the system as well as the accuracy of the adjusting. The practical experience indicated that increasing the value of $K_{p}$ was able to improve the system responding speed as well as the adjusting accuracy; decreasing the value of $K_{p}$ would reduce the overshoot, leading to a longer adjusting time. From that the fuzzy regular table of $K_{p}$ was constructed as:

Table 1 the fuzzy regular table of $K_{p}$

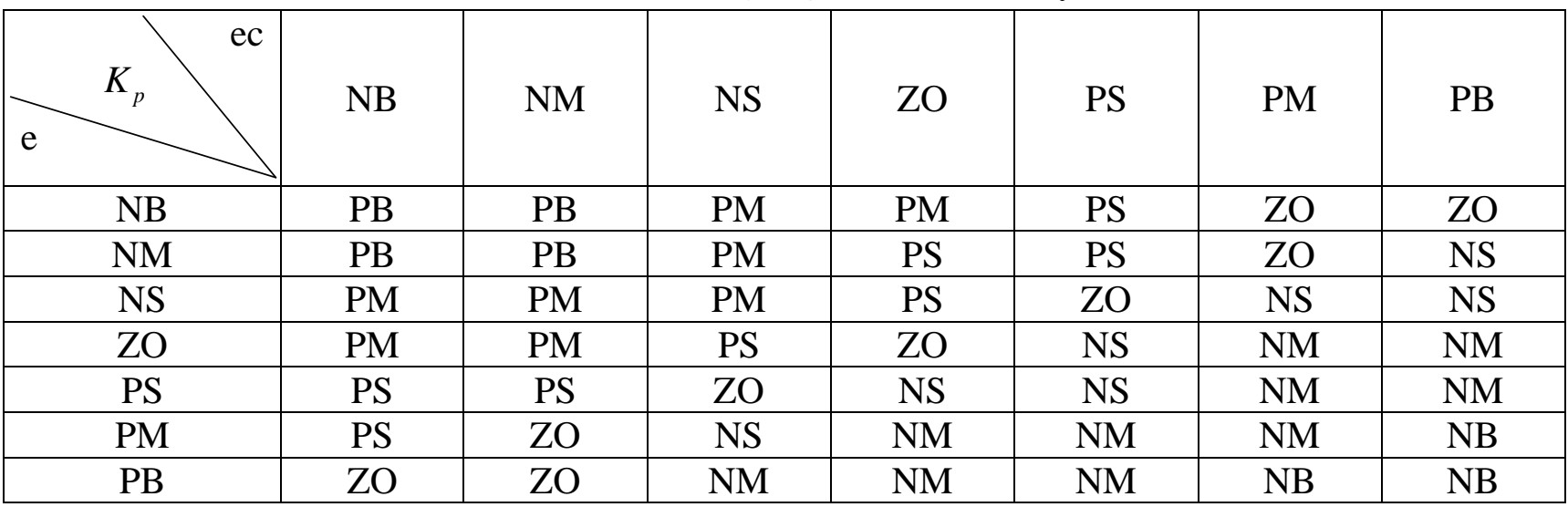

Integral action coefficient $K_{i}$ was related to the static deviation of the system. The practical application indicated that using a larger value of $K_{i}$ could raise the integral speed, meanwhile speed up the diminishing speed of system static deviation; taking smaller value of $K_{i}$ would weaken the integral action, slow down the diminishing speed of system static deviation and finally lead to a lower system adjusting accuracy and weaker dynamical characteristics. The principals above constructed the controlling regulars followed:

Table 2 controlling regular table of $K_{i}$

\begin{tabular}{|c|c|c|c|c|c|c|c|}
\hline & NB & NM & NS & ZO & PS & PM & PB \\
\hline NB & & & & & & & \\
\hline NM & NB & NB & NB & NM & NS & ZO & ZO \\
\hline NS & NB & NB & NM & NS & NS & ZO & PS \\
\hline ZO & NM & NM & NS & ZS & ZO & PS & PS \\
\hline PS & NM & NS & ZO & PS & PS & PM & PM \\
\hline PM & ZO & ZO & PS & PS & PM & PB & PB \\
\hline PB & ZO & PS & PS & PM & PB & PB & PB \\
\hline
\end{tabular}

Differential coefficient $K_{d}$ was related to the dynamical characteristics of the system. Suitable value of $K_{d}$ was able to strengthen the system dynamical characteristics. Varying $K_{d}$ would change the deviation varying rate ec, when deviation changed, it could be braked in advance, decreased overshoot, kept the system steady. When taking a $K_{d}$ that was too small, the system would unable to brake, leading to an increasing overshoot. From what was described above, the fuzzy adjusting regular for the parameter $K_{d}$ was: 
Table 3 the controlling regular table for $K_{d}$

\begin{tabular}{|c|c|c|c|c|c|c|c|}
\hline \multicolumn{1}{|c|}{$K_{d}$} & NB & NM & NS & ZO & PS & PM & PB \\
\hline NB & & & & & & \\
\hline NM & PS & NB & NB & NB & NB & NM & PS \\
\hline NS & ZO & NS & NB & NM & NM & NS & ZO \\
\hline ZO & ZO & NS & NS & NS & NS & NS & ZO \\
\hline PS & ZO & ZO & ZO & ZO & ZO & ZO & ZO \\
\hline PM & PB & NS & PS & PS & PS & PS & PB \\
\hline PB & PB & PM & PM & PM & PS & PS & PB \\
\hline
\end{tabular}

\section{Fuzzy deduction and strategy}

After obtaining the adjusting regulars of the three ones, which were then been carried out to combine the arithmetic based on the fuzzy theory to obtain the relative three controlling tables of $K_{p}, K_{i}$ and $K_{d}$.

Table 4 fuzzy controlling inquiring table of $K_{p}$

\begin{tabular}{|c|c|c|c|c|c|c|c|c|c|c|c|c|c|}
\hline $\begin{array}{c}\mathrm{ec} / \\
K_{p} / \mathrm{e}\end{array}$ & -6 & -5 & -4 & -3 & -2 & -1 & 0 & 1 & 2 & 3 & 4 & 5 & 6 \\
\hline-6 & 6 & 6 & 6 & 6 & 4 & 4 & 3 & 2 & 2 & 0 & 0 & 0 & 0 \\
\hline-5 & 6 & 6 & 6 & 5 & 4 & 4 & 3 & 2 & 2 & 0 & 0 & 0 & 0 \\
\hline-4 & 6 & 6 & 5 & 5 & 4 & 3 & 2 & 2 & 1 & 0 & 0 & -1 & -2 \\
\hline-3 & 6 & 5 & 5 & 5 & 3 & 3 & 2 & 1 & 1 & 0 & 0 & -1 & -2 \\
\hline-2 & 4 & 4 & 4 & 4 & 4 & 3 & 2 & 1 & 0 & -1 & -1 & -1 & -2 \\
\hline-1 & 4 & 4 & 3 & 3 & 3 & 3 & 1 & 1 & 0 & -1 & -2 & -2 & -2 \\
\hline 0 & 4 & 3 & 3 & 3 & 2 & 2 & 0 & -1 & -2 & -3 & -4 & -4 & -4 \\
\hline 1 & 2 & 2 & 2 & 1 & 0 & 0 & -1 & -1 & -2 & -3 & -3 & -3 & -4 \\
\hline 2 & 2 & 2 & 1 & 1 & 0 & 0 & -1 & -2 & -2 & -3 & -4 & -4 & -4 \\
\hline 3 & 2 & 2 & 0 & 0 & -1 & -1 & -3 & -3 & -3 & -4 & -4 & -5 & -5 \\
\hline 4 & 2 & 1 & 0 & 0 & -1 & -2 & -3 & -3 & -4 & -4 & -4 & -5 & -6 \\
\hline 5 & 0 & 0 & 0 & 0 & -3 & -3 & -4 & -4 & -4 & -5 & -5 & -5 & -6 \\
\hline 6 & 0 & 0 & 0 & 0 & -3 & -4 & -4 & -4 & -4 & -5 & -6 & -6 & -6 \\
\hline
\end{tabular}

Table 5 fuzzy controlling inquiring table of $K_{i}$

\begin{tabular}{|c|c|c|c|c|c|c|c|c|c|c|c|c|c|}
\hline $\begin{array}{c}\mathrm{ec} / \\
K_{\mathrm{i}} / \mathrm{e}\end{array}$ & -6 & -5 & -4 & -3 & -2 & -1 & 0 & 1 & 2 & 3 & 4 & 5 & 6 \\
\hline-6 & -6 & -6 & -6 & -6 & -6 & -5 & -4 & -2 & -2 & 0 & 0 & 0 & 0 \\
\hline-5 & -6 & -6 & -6 & -6 & -5 & -5 & -4 & -2 & -1 & 0 & 0 & 0 & 0 \\
\hline-4 & -6 & -6 & -5 & -5 & -4 & -3 & -2 & -2 & -1 & 0 & 0 & 1 & 1 \\
\hline-3 & -6 & -5 & -5 & -5 & -3 & -3 & -2 & -1 & -1 & 0 & 0 & 1 & 2 \\
\hline-2 & -5 & -5 & -4 & -3 & -3 & -3 & -2 & 0 & 0 & 1 & 1 & 1 & 2 \\
\hline-1 & -5 & -5 & -3 & -3 & -3 & -3 & -1 & 0 & 0 & 1 & 1 & 2 & 2 \\
\hline 0 & -4 & -4 & -3 & -3 & -2 & -1 & 0 & 1 & 2 & 3 & 4 & 5 & 6 \\
\hline 1 & -4 & -3 & -2 & -1 & 0 & 0 & 1 & 1 & 2 & 3 & 3 & 5 & 5 \\
\hline 2 & -3 & -3 & -1 & -1 & 0 & 0 & 2 & 2 & 2 & 3 & 4 & 5 & 6 \\
\hline 3 & 0 & 0 & 0 & 0 & 1 & 2 & 2 & 3 & 4 & 5 & 5 & 5 & 6 \\
\hline 4 & 0 & 0 & 0 & 0 & 2 & 2 & 2 & 4 & 4 & 5 & 5 & 6 & 6 \\
\hline 5 & 0 & 0 & 1 & 1 & 2 & 2 & 3 & 5 & 5 & 5 & 6 & 6 & 6 \\
\hline 6 & 0 & 0 & 1 & 2 & 2 & 2 & 4 & 5 & 5 & 6 & 6 & 6 & -6 \\
\hline
\end{tabular}


Table 6 fuzzy controlling inquiring table of $K_{d}$

\begin{tabular}{|c|c|c|c|c|c|c|c|c|c|c|c|c|c|}
\hline $\begin{array}{c}\mathrm{ec} / \\
K_{d} / \mathrm{e}\end{array}$ & -6 & -5 & -4 & -3 & -2 & -1 & 0 & 1 & 2 & 3 & 4 & 5 & 6 \\
\hline-6 & 2 & 1 & -6 & -6 & -6 & -6 & -6 & -5 & -5 & -4 & -3 & -2 & -1 \\
\hline-5 & 1 & 1 & -5 & -5 & -6 & -6 & -6 & -5 & -5 & -3 & -3 & -1 & -1 \\
\hline-4 & 1 & 1 & -6 & -5 & -5 & -5 & -4 & -4 & -3 & -2 & -1 & 0 & 0 \\
\hline-3 & 1 & 1 & -5 & -5 & -5 & -5 & -3 & -3 & -3 & -1 & -1 & 0 & 0 \\
\hline-2 & 0 & 0 & -1 & -2 & -4 & -4 & -3 & -2 & -2 & -1 & -1 & 0 & 0 \\
\hline-1 & 0 & 0 & -1 & -1 & -3 & -4 & -3 & -2 & -1 & -1 & -1 & 0 & 0 \\
\hline 0 & 0 & 0 & -1 & -1 & -1 & -2 & -2 & -2 & -1 & -1 & -1 & 0 & 0 \\
\hline 1 & 0 & 0 & 0 & 0 & 0 & 0 & 0 & 0 & 0 & 0 & 0 & 0 & 0 \\
\hline 2 & 0 & 0 & 0 & 0 & 0 & 0 & 0 & 0 & 0 & 0 & 0 & 0 & 0 \\
\hline 3 & 5 & 5 & -1 & -1 & 1 & 1 & 1 & 1 & 1 & 2 & 2 & 5 & 6 \\
\hline 4 & 5 & 5 & -1 & -1 & 1 & 1 & 1 & 1 & 1 & 2 & 2 & 6 & 6 \\
\hline 5 & 6 & 6 & 4 & 3 & 3 & 3 & 3 & 2 & 2 & 2 & 2 & 6 & 6 \\
\hline 6 & 6 & 6 & 4 & 4 & 4 & 4 & 3 & 2 & 2 & 2 & 2 & 6 & 6 \\
\hline
\end{tabular}

\section{Software realization}

During the online operating process, the control system completed online self-correcting for PID parameters by solving, checking table and calculating the results of the fuzzy logic rules. The working flow chart was shown in Fig. 4.

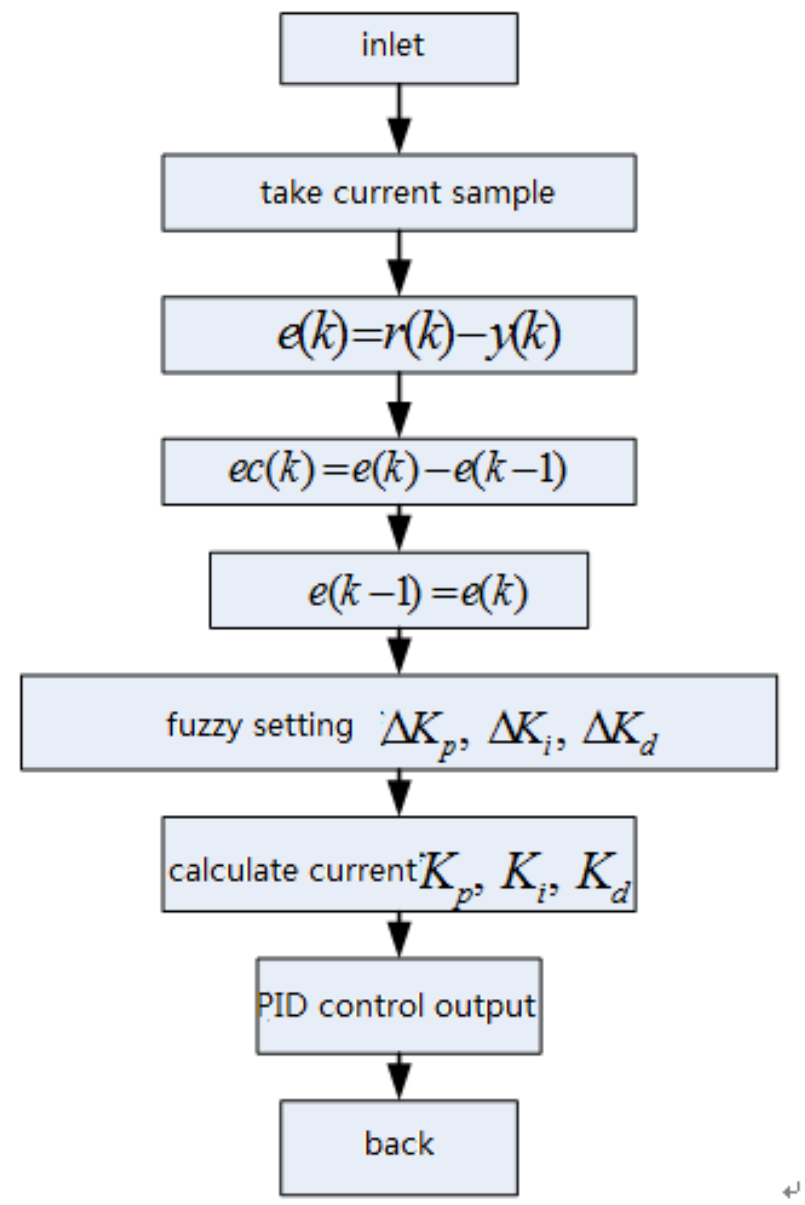

Fig.4. Self-adapting fuzzy PID control program flow chart

\section{Simulation result analysis}

Neglecting the system friction and load influence, utilized the control system simplified math model deduced in this article, then carried out system simulation research in the environment of 
Matlab/Simulink, with two conditions of non-self-adapting fuzzy PID control and applying self-adapting fuzzy PID control method, gave out the responding curves of stepped signal and sine following signal.

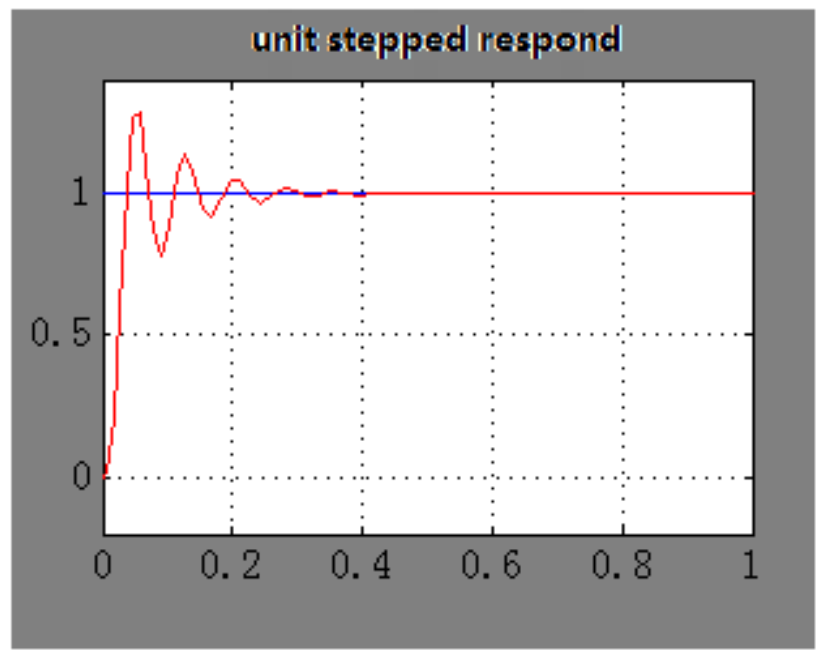

Fig.5. Unit stepped respond of the system

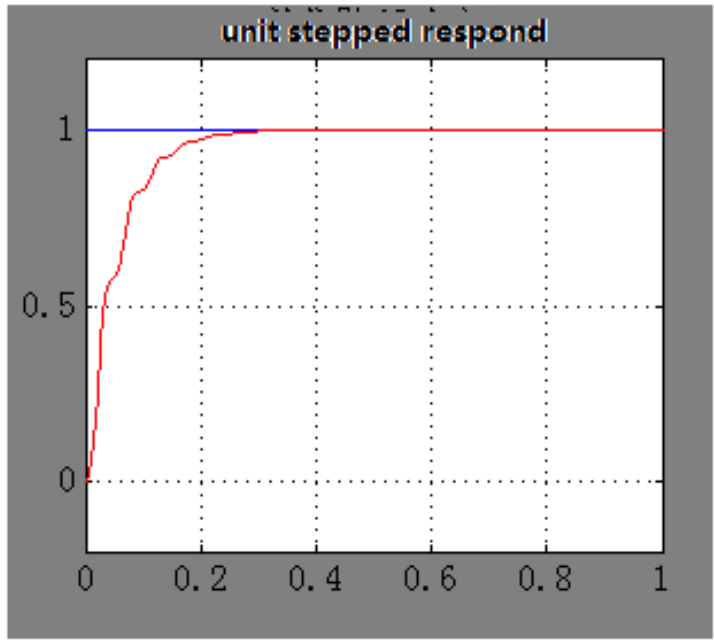

Fig.6. Unit stepped respond of self-adapting fuzzy PID control system

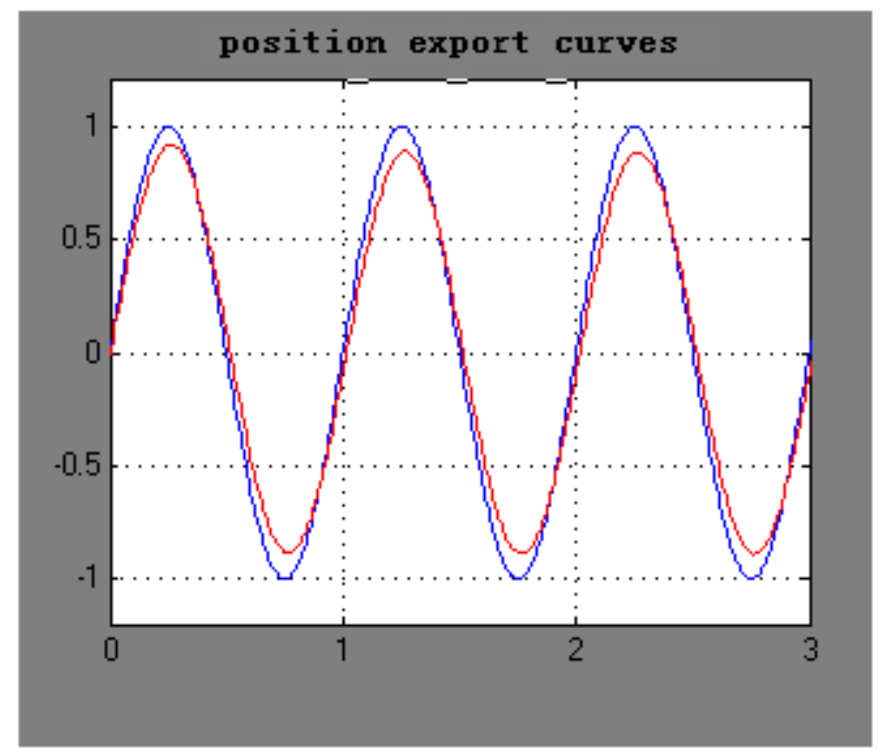

Fig.7 System position following curves 


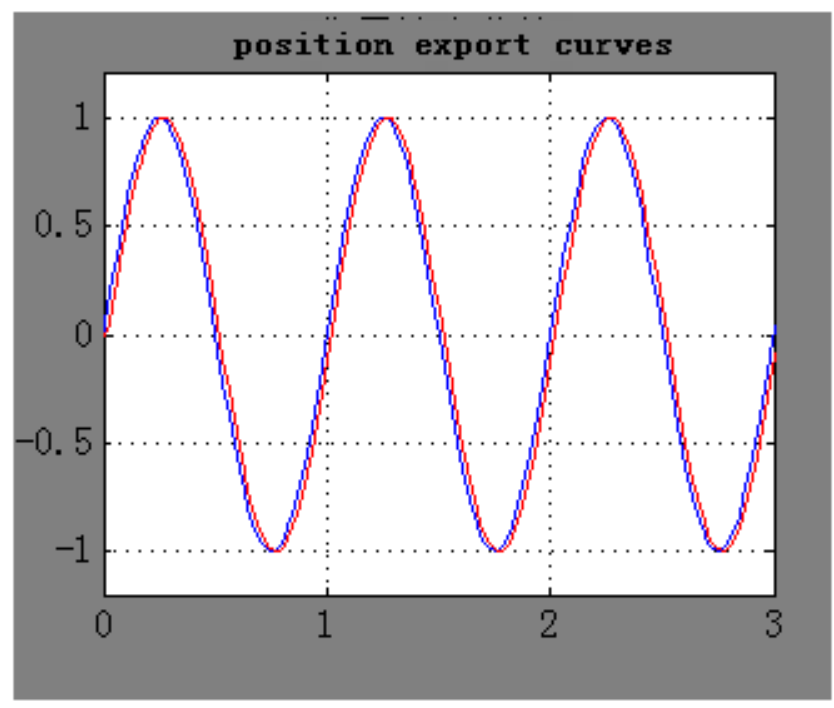

Fig.8. Self-adapting fuzzy PID control system position following curves

From Fig.5 it could be seen that no-calibrating system overshoot $\sigma=30 \%$, adjusting time $\mathrm{t}=$ $0.18 \mathrm{~s}$, responding speed was fast, but the overshoot was too large, the static accuracy was unable to satisfy the technology requirement of control system. after adding self-adjusting fuzzy PID control strategy, as was shown in Fig.6, system had no overshoot, the static accuracy improved, responding speed nearly unchanged, which satisfied the system requirement. From Fig.7 and Fig.8 it could be seen that after adding self-adjusting fuzzy PID control strategy, system deviation became smaller, following effect became better.

\section{Conclusion}

In this article a type of adjustable blade angle control system which had been successfully applied to the aeroengine component tests was described, the system was made up of electro-hydraulic servo valve, actuating cylinder, displacement transducer, servo amplifier, ADAM modules, control calculation, etc. the system applied hydraulic control method, satisfied the test requirement of large power, fast accurate respond. The control software was programmed using $\mathrm{VC}++$.net, the control computer accomplished giving valve control signal and feedback of the displacement transducer through RS232 communication port. After fully considering a series of disadvantageous factors such as the non linearity of the system as well as the uncertainty of the parameters, the control regular of the system applied self-adapting fuzzy PID control method, it was able to restrain the influence of the system in an extremely large degree, fit the parameter influence imposed on the controlled system. Meanwhile, aiming to the core part of the angle control system, namely the self-adapting fuzzy PID control, detailed control regulars were given in this article, combined with detailed design method.

In the practical engineering application, the adjustable blade angle control system referred in this article could perfectly satisfied the requirement of aeroengine test to blade control, fully improved the utility of the system as well as the feasibility of the control method. Considering that in the future aeroengine test will become more complex with no doubt, the requirement to the adjustable blade technology will be more serious. Since self-adapting fuzzy PID control did not require accurate math model, the parameterization of the controlled object had a strong adaptability, and even when the structure of the object model had a big change, a reasonable control effect could be obtained. Because of these advantages, in the future it will of course play an important role in the highly complicate adjustable blade technology.

\section{References}

[1] Xu Sheng. Digital PWM speed regulation system for DC motor and its fuzzy control algorithm. Master thesis: Huazhong University Of Science And Technology, 2006. 
[2] Mao Bo. Study on self-learning fuzzy control strategy for electro-hydraulic servo system. Master thesis: Yanshan University, 2011.

[3] Song Fengmin. Study on electro-hydraulic servo fuzzy control system of hydraulic cylinder assembling specialized equipment. Master thesis: Shandong University of Technology, 2007.

[4] Qian Yanghui. Research of control strategy based on the electro-hydraulic proportional position control system. Master thesis: Donghua University, 2012.

[5] Chen Lihua. Fuzzy control and experimental research on multipurpose electro-hydraulic servo system. Master thesis: Harbin University of Science and Technology. 2006. 